\title{
Factors Associated with Failure to Achieve SVR in Hepatitis C Genotype 3 Patients Within an Integrated Care Delivery System
}

\author{
T. Craig Cheetham, PharmD, MS; Fang Niu, MS; Kevin Chiang, PharmD, MBA; Yong Yuan, PhD; \\ Anu Kalsekar, MS; Rulin Hechter, MD, PhD; Joel W. Hay, PhD; and Lisa Nyberg, MD, MPH
}

\begin{abstract}
BACKGROUND: Achievement of sustained virologic response (SVR) and factors associated with treatment failure in hepatitis $\mathrm{C}$ virus (HCV) genotype 3 have been described in tertiary and referral care settings, with rates of SVR reported to range between $72 \%$ and $89 \%$. Fewer data exist on SVR outside of these settings.

OBJECTIVE: To describe rates of SVR and characterize factors associated with achievement of SVR within an integrated health care delivery system.

METHODS: A retrospective cohort study of genotype $3 \mathrm{HCV}$ patients treated with dual therapy (pegylated interferon-alpha plus ribavirin) was conducted at Kaiser Permanente Southern California. Adult patients diagnosed with HCV and testing positive for HCV-RNA genotype 3 were identified from electronic medical records. Data were collected on patient demographics, baseline health status, and comorbid conditions. A multivariate logistic regression model was used to determine the association between baseline patient factors and SVR.
\end{abstract}

RESULTS: A total of $484 \mathrm{HCV}$ genotype 3 patients met the eligibility criteria. The median age was 49 years, and $65.7 \%$ were male. Overall, $252(52.1 \%)$ achieved SVR. Aged $\geq 45$ years and male gender were associated with lower rates of SVR; cirrhosis and chronic diseases (diabetes and chronic obstructive pulmonary disease) were also associated with lower rates of SVR.

CONCLUSIONS: SVR was lower in patients within an integrated care delivery system than in those in tertiary and referral centers. Males and older patients had lower rates of SVR, as well as patients with cirrhosis, diabetes, and chronic obstructive pulmonary disease.

J Manag Care Spec Pharm. 2015;21(8):641-47

Copyright $\odot 2015$, Academy of Managed Care Pharmacy. All rights reserved.

\section{What is already known about this subject}

It is increasingly recognized that patients with hepatitis $C$ virus (HCV) genotype 3 are at higher risk for developing hepatic complications.

Sustained virologic response (SVR) rates in the range of $72 \%$ $89 \%$ are reported for genotype $3 \mathrm{HCV}$ from clinical trials and in tertiary care or referral settings. Relapse rates in these settings are generally in the 10\%-15\% range. Less is known about SVR rates and relapse rates for genotype $3 \mathrm{HCV}$ outside of these settings. Patient characteristics such as cirrhosis, fibrosis, steatosis, obesity, diabetes, race, and viral load have been associated with lower rates of SVR.

\section{What this study adds}

Within an integrated care delivery system, this study found that the SVR rate for HCV genotype 3 was $52 \%$, which is much lower than previously reported.

Almost 1 in 4 patients (23.5\%) with genotype 3 relapsed after completing their treatment course, which is higher than reports from tertiary care settings.

Cirrhosis, diabetes, and chronic obstructive pulmonary disease were associated with significantly lower rates of SVR; male patients and patients aged 45 years or older also had lower SVR rates.

For HCV genotype 3, real-world data on SVR and relapse rates differ from results reported in clinical trials.

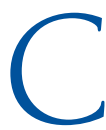
urrent estimates indicate that between 2.3 and 3.2 million persons in the United States are chronically infected with hepatitis C virus (HCV). ${ }^{1,2}$ Although the most common genotype is 1 , a significant percentage of U.S. patients are infected with genotype 3. Based on data from a national reference testing laboratory study and 2 population studies, genotype 3 makes up between 12\% and 13\% of chronic HCV patients in the United States. ${ }^{3-5}$ From these reports, it can be estimated that somewhere between 300,000 and 400,000 individuals are chronically infected with HCV genotype 3. This is important because recent evidence suggests that hepatic complications are higher in HCV genotype 3.

Genotype 3 has been associated with a higher incidence of steatosis and a more rapid progression of hepatic fibrosis. ${ }^{6}$ In a recent meta-analysis, the odds ratio for accelerated progression to liver fibrosis, based on single biopsy studies, was higher for genotype 3 compared with other genotypes. ${ }^{7}$ Other studies have identified high rates of liver complications associated with those patients infected with HCV genotype 3. Nkontchou et al. (2011) found that HCV genotype 3 patients with cirrhosis had a higher incidence of hepatocellular carcinoma. ${ }^{8}$ Evidence from the Veterans Affairs Clinical Hepatitis C Registry suggests that patients infected with genotype 3 are at a higher risk for cirrhosis, decompensated cirrhosis, and hepatocellular cancer., ${ }^{9,10}$

Although these patients are at a potentially higher risk for complications, genotype 3 is generally responsive to treatment with the combination pegylated interferon-alpha (PegINF) and ribavirin. Rates of sustained virologic response (SVR) in 
the $72 \%-89 \%$ range are reported for genotype $3 \mathrm{HCV}$ patients treated with PegINF and ribavirin. ${ }^{11-18}$ However, these SVR results are from clinical trials or from patients treated at tertiary medical centers, university hospitals, and referral centers. ${ }^{11-18}$ There is little information confirming these rates of SVR response in population-based studies.

The purpose of this study was to evaluate the rates of SVR and the factors associated with SVR in a population of patients treated outside of the tertiary care and referral medical care settings. Patients with chronic HCV genotype 3 and treated with the combination of PegINF plus ribavirin, within an integrated health care delivery system, were included in the study.

\section{Methods}

\section{Setting}

This retrospective cohort study consisted of chronic HCV genotype 3 patients who were treated with dual therapy consisting of PegINF and ribavirin and was conducted at Kaiser Permanente Southern California (KPSC). KPSC is a large nonprofit integrated health care delivery system providing health care services to approximately 3.7 million members in southern California. Medical care is provided through its own facilities, which include 14 hospitals and approximately 200 outpatient clinics. All aspects of care and interactions with the health care delivery system are captured in a comprehensive electronic medical record (EMR). In addition, care delivered in non-Kaiser settings is captured within a claims reimbursement system. The data generated through the EMR are available for research purposes and include information on membership/ benefits, demographics, dispensed prescriptions, coded diagnoses and procedures, and laboratory test results. This study was approved by the KPSC Institutional Review Board, which waived the requirement of informed consent, since this was a database study without direct patient contact.

\section{Patients}

The KPSC membership is diverse and closely mirrors the overall southern California population with respect to age, race, education, and income. ${ }^{19}$ Patients with a diagnosis of chronic $\mathrm{HCV}$ and/or laboratory test results confirming HCV genotype 3 between January 1, 2007, and December 31, 2012, were screened for inclusion in the study. Eligible patients needed to fill at least 1 prescription for either ribavirin or PegINF, and the date of the first prescription was defined as the index date. Patients needed to be aged at least 18 years on the index date. In addition, patients were required to have at least 12 months of continuous membership plus drug benefit in KPSC prior to the index date to allow for capture of baseline information. Only patients with a baseline and follow-up viral load test (HCVRNA) after the index date were included in the analysis. Patients coinfected with hepatitis B were also excluded from the cohort due to the complexity of treatment associated with coinfected patients and their higher risk for hepatic complications.

\section{Data}

Treatment courses for HCV therapy were based on dispense dates and days of supply in the pharmacy records. A gap rule of 6 months was used to designate distinct courses of therapy; the gap rule measured time from the end of the last prescription (dispense date plus days of supply) until the time of the next dispense date for either PegINF or ribavirin. This 6-month rule was selected to allow evaluation of response to therapy. All patients needed to initiate and complete their treatment courses between January 1, 2007, and December 31, 2012. Only the first course of treatment was included in the analysis for those receiving more than 1 course during the study window. Patients were designated as either treatment naive or treatment experienced based on prior HCV treatment. For purposes of this study, data were collected as far back as January 2002 to identify prior HCV treatment within Kaiser Permanente.

Data on demographics (age, sex, and race/ethnicity) and baseline comorbid conditions were collected during the 12 months prior to the index date. Comorbid conditions and laboratory test results were captured, which included cirrhosis, steatosis, FIB-4 score (a marker of hepatic fibrosis), ${ }^{10,20}$ serum liver enzymes (aspartate aminotransferase and alanine aminotransferase), alcohol abuse, platelet count, history of liver transplant, viral load (HCV-RNA), year treatment was initiated, chronic obstructive pulmonary disease, renal insufficiency (chronic kidney disease 3, 4, or 5), diabetes, obesity, and human immunodeficiency virus (HIV) coinfection. Diseases such as cirrhosis, steatosis, diabetes, HIV coinfection, and chronic obstructive pulmonary disease were identified using International Classification of Diseases, Ninth Revision, Clinical Modification (ICD-9-CM) codes. Chronic kidney disease was captured using a combination of ICD-9-CM codes and estimated glomerular filtration rate, while obesity was determined by recorded body mass index or ICD-9-CM codes. Laboratory test results were retrieved from inpatient and outpatient care settings. The number of unique prescription products and outpatient visits in the previous 12 months, as an estimate of health care utilization, were also captured from the medical record. The Quan adaptation of the Charlson Comorbidity Index (CCI) was calculated as an estimate of health status. ${ }^{21-23}$

The primary outcome was SVR 24 weeks after completion of a treatment course. For this study, HCV-RNA tests performed between 12 weeks and 36 weeks after treatment completion were screened to determine the primary SVR outcome $(24 \pm 12$ weeks). If multiple HCV-RNA tests were performed in this time window, then the last test performed was used to determine SVR. Patients who initiated a new course of therapy within this time window were classified as a failure. In an effort to 


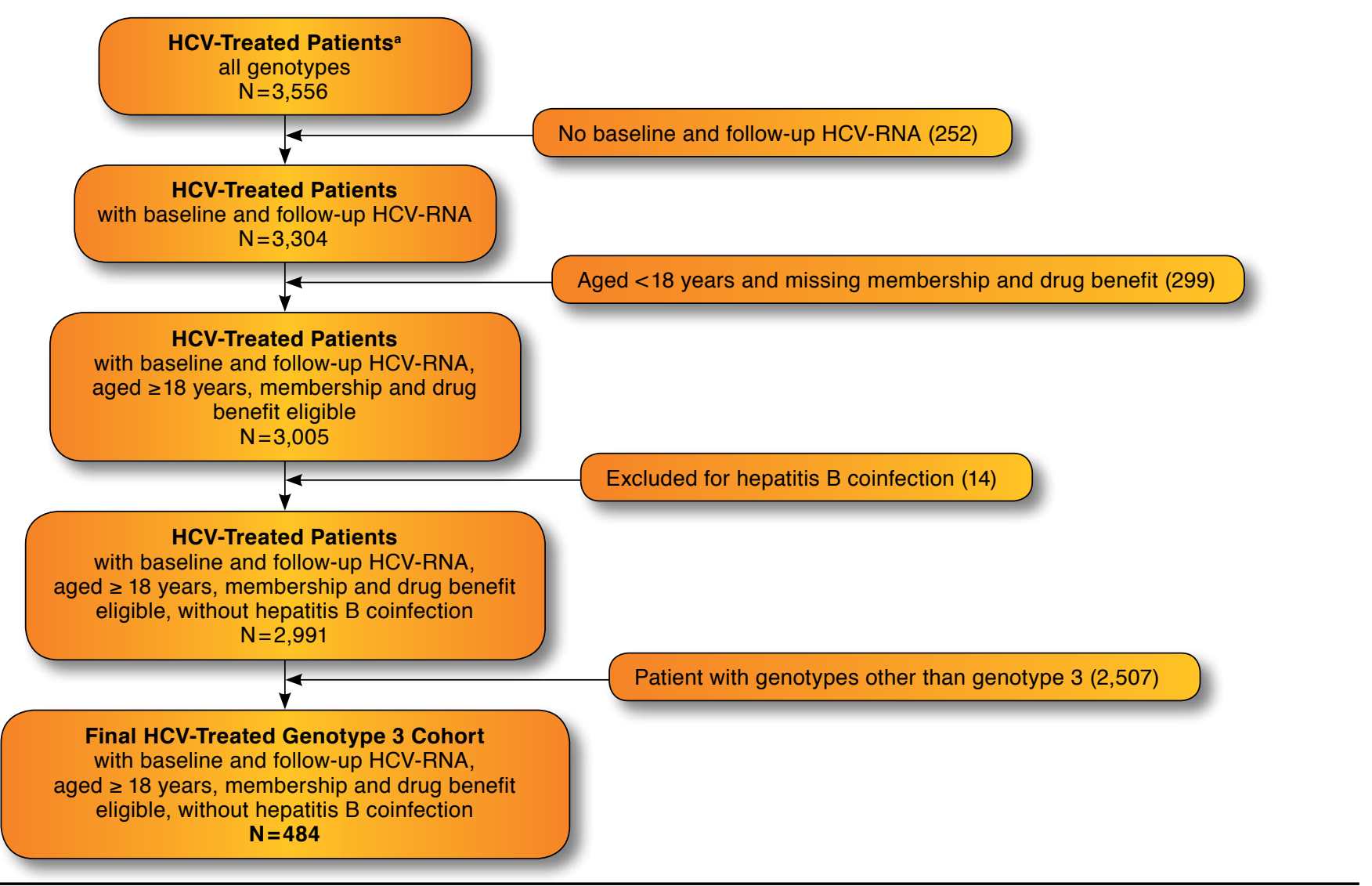

a Diagnosed and treated (patients needed to start and complete therapy between January 1, 2007, and December 31, 2012.

$H C V=$ hepatitis $C$ virus; HCV-RNA= viral load test that detects the hepatitis $C$ virus.

determine outcomes, chart reviews were conducted on patients who had nondetectable viral loads at the end of treatment but no HCV-RNA tests in the 12- to 36-week time interval. If patients had HCV-RNA tests beyond the 36-week time window, had continuous membership, and had no evidence of additional treatment, they were classified as SVR or relapse based on these test results. Patients who had cleared the virus at the end of therapy but were lost to follow-up or no longer had health plan membership remained identified as virus cleared at end of therapy but were classified as treatment failure. Treatment failure-those without SVR-were divided into the following groups: (a) virus never cleared (during the course of treatment); (b) breakthrough (virus initially cleared but then returned while on treatment); and (c) relapse (virus was cleared at the end of therapy but returned after stopping treatment). A fourth group was added (cleared, virus cleared at end of therapy) for those patients who had cleared the virus at the end of therapy but never returned for follow-up viral load tests and confirmationthese patients were classified as treatment failures.

\section{Statistical Analysis}

The baseline characteristics of patients with chronic HCV genotype 3 are described along with a comparison between those with SVR and those with treatment failure. The overall SVR rate and frequency of relapse, breakthrough, and failure are reported. A multivariate logistic regression model was generated with SVR as the dependent variable. Potential risk factors for the model included demographic information (age, gender, and race/ethnicity); indices of liver disease severity (cirrhosis, steatosis, FIB-4 score $>3.25$, and liver transplant); viral load; concomitant diseases (chronic obstructive pulmonary disease, renal insufficiency, diabetes, obesity, and HIV); the number of outpatient visits; and CCI. In this analysis, age was divided into $<45$ years and $\geq 45$ years to capture the baby-boomer cohort (a population with a higher prevalence of HCV). For the final model, a backward selection process was used to determine major factors to include, and other factors were added based on their clinical importance. Odds ratio (OR) and 95\% confidence intervals $(95 \% \mathrm{CI}$ ) for predictors of not achieving SVR 


\begin{tabular}{|c|c|c|}
\hline Outcome, $n$ & $\mathrm{~N}=484$ & Percentage \\
\hline Sustained virologic response & 252 & 52.1 \\
\hline Treatment failure & 232 & 47.9 \\
\hline Virus never cleared & 34 & 7.0 \\
\hline Breakthrough & 12 & 2.5 \\
\hline Relapse & 114 & 23.5 \\
\hline Virus cleared at end of therapy & 72 & 14.9 \\
\hline
\end{tabular}

from the logistic regression model are reported. All analyses were conducted using SAS 9.2 software (SAS Institute, Cary, NC). A two-sided $P$ value $<0.05$ was considered statistically significant.

\section{Results}

A total of 2,991 treated individuals met all of the inclusion and exclusion criteria, and from this population of patients, 484 (16.2\%) were identified with genotype 3 (Figure 1). All patients were treated with the combination PegINF and ribavirin, and the median duration of therapy was 25 weeks. SVR was achieved in 252 (52.1\%) patients with genotype 3. A breakdown of the $232(47.9 \%)$ treatment failures is included in Table 1. Of the 232 failures, 34 never cleared the virus during treatment, and another 114 (23.5\%) relapsed after completing treatment. A total of 72 patients (14.9\% of all treated patients) were classified "virus cleared at the end of therapy" but did not have a follow-up viral load laboratory test. Most of the patients without follow-up $(n=50)$ had lost or did not continue their membership in the health plan; 3 patients died; and the remainder did not return to the clinic for HCV-RNA laboratory testing.

The baseline characteristics of the genotype 3 population, stratified by SVR and those who failed therapy, are included in Table 2. The average age of the population was aged 49 years, and $65 \%$ were male. Very few individuals in our population of genotype 3 patients had a prior liver transplant, were coinfected with HIV, or had chronic kidney disease (CKD), defined as CKD grade $\geq 3$. Compared with patients who achieved SVR, a significantly higher percentage of patients with chronic diseases (pulmonary disease and diabetes), liver cirrhosis, and a high FIB-4 score failed therapy. Prior HCV treatment and overall health care utilization (hospitalizations and emergency room visits, outpatient visits, and prescription drug use) were equivalent between those with SVR and those who failed therapy.

In the multivariate analysis, patients aged $\geq 45$ years had a $43 \%$ lower likelihood of SVR, while male patients had a $36 \%$ lower likelihood of SVR (Table 3). Patients with chronic diseases and severe liver conditions also had lower SVR rates. The OR (95\% CI) for individuals with pulmonary disease and those with diabetes was 0.39 (0.19-0.80) and 0.34 (0.17-0.69), respectively. The OR $(95 \% \mathrm{CI})$ for SVR for patients with cirrhosis was $0.31(0.15-0.61)$.

\section{Discussion}

In this study of 484 patients with HCV genotype 3, 52.1\% achieved SVR on dual therapy consisting of PegINF and ribavirin. This rate is lower than other reports from tertiary medical centers, referral centers, and clinical trials, where SVR rates have been reported to range between $72 \%$ and $89 \%{ }^{11-16,24}$ One potential reason for the low SVR rate was the high relapse rate $(23.5 \%)$ in our patient population compared with rates reported by others. Relapse rates in the range of $10 \%$ to $15 \%$ for genotype 3 are generally reported in the literature. ${ }^{13,15-17} \mathrm{We}$ were not able to discern the reason for our higher relapse rates, although adherence to PegINF and ribavirin was considered; when checking patient medication refill patterns, adherence appeared to be high in our population. Another potential reason is the high number of patients who were lost to follow-up or did not respond to repeated efforts to get them to return for post-treatment laboratory testing $(n=72)$. Patients who cleared the virus at the end of therapy but were lost to follow-up were not counted as SVR. If, however, we were to apply our relapse rate to the patients who were lost to follow-up, then 53 additional patients could be assumed to have achieved SVR, and our overall SVR rate would increase to 63\% (a rate that is closer to other reports).

Overall, the comorbid conditions found in our population are consistent with what has been reported for treated HCV genotype 3 patients of this age and sex distribution. In the multivariate analysis, we identified several factors that were associated with lower rates of SVR. Patient with diabetes, pulmonary disease, and cirrhosis had significantly lower SVR rates with ORs significantly below 1 . In addition, patients with high viral loads and those who were obese had lower rates of SVR, but the ORs did not reach statistical significance. Older age ( $\geq 45$ years) and male sex were also associated with ORs significantly lower than 1 . These findings are consistent with those reported from tertiary and referral medical settings. For example, others have reported that patients with various degrees of liver disease, such as cirrhosis, advanced fibrosis, steatosis, and obesity, have lower SVR rates in genotype 3. ${ }^{11-16,25}$ Age less than 45 years has been associated with improved SVR outcomes in genotype $3 .^{16}$

It is increasingly reported that HCV genotype 3 is more difficult to treat than previously thought and is associated with higher rates of complications than most other genotypes.9,26,27 Two recent reviews that focused exclusively on HCV genotype 3 concluded that these patients are at increased risk for rapid progression of liver disease (steatosis, fibrosis, and hepatocellular cancer) and that efforts should be made for more efficacious and targeted genotype 3 treatments. ${ }^{26,27}$ The results of our study, which evaluated dual therapy with PegINF and ribavirin 
TABLE 2 Baseline Characteristics: Univariate Predictors of SVR

\begin{tabular}{|c|c|c|c|c|c|c|c|}
\hline & \multicolumn{2}{|c|}{ SVR } & \multirow{2}{*}{$\begin{array}{c}P \\
\text { Value }\end{array}$} & & \multicolumn{2}{|c|}{ SVR } & \multirow{2}{*}{$\begin{array}{c}P \\
\text { Value }\end{array}$} \\
\hline & Yes & No & & & Yes & No & \\
\hline Number of patients & $\mathrm{n}=252$ & $\mathrm{n}=232$ & & Viral load, n (\%) & & & $0.180^{\mathrm{b}}$ \\
\hline Age at index & & & $0.002^{\mathrm{a}}$ & $<400,000 \mathrm{IU} / \mathrm{mL}$ & $137(55.0)$ & $112(45.0)$ & \\
\hline Mean (SD) & $46.8 \quad(9.3)$ & $49.4 \quad(7.9)$ & & $\geq 400,000 \mathrm{IU} / \mathrm{mL}$ & $115(48.9)$ & $115(51.1)$ & \\
\hline Median & 48 & 50 & & Steatosis, $\mathrm{n}(\%)$ & $16(45.7)$ & $19(54.3)$ & $0.430^{\mathrm{b}}$ \\
\hline Age category, n (\%) & & & $0.002^{b}$ & Cirrhosis, n (\%) & $18(24.3)$ & $56(75.7)$ & $<0.001^{\mathrm{b}}$ \\
\hline$<45$ & $87(63.0)$ & $51(37.0)$ & & Liver transplant, n (\%) & $5(62.5)$ & $3(37.5)$ & $0.550^{\mathrm{b}}$ \\
\hline$\geq 45$ & $165(52.3)$ & $181(47.7)$ & & Alcohol abuse, n (\%) & $37(49.3)$ & $38(50.7)$ & $0.610^{\mathrm{b}}$ \\
\hline Gender, n (\%) & & & $0.040^{\mathrm{b}}$ & Pulmonary disease, n (\%) & $15(35.7)$ & $27(64.3)$ & $0.030^{\mathrm{b}}$ \\
\hline Female & $97(58.4)$ & $69(41.6)$ & & Prior HCV treatment, n (\%) & $10(43.5)$ & $13(56.5)$ & $0.400^{\mathrm{b}}$ \\
\hline Race, n (\%) & & & $0.830^{\mathrm{b}}$ & Diabetes, n (\%) & $14(25.0)$ & $42(75.0)$ & $<0.001^{\mathrm{b}}$ \\
\hline White & $138(53.3)$ & $121(46.7)$ & & Renal insufficiency (CKD), n (\%) & & & $0.670^{\mathrm{b}}$ \\
\hline Hispanic/black & $60(51.3)$ & $57(48.7)$ & & 1 and 2 & $246(52.2)$ & $225(47.8)$ & \\
\hline Asian/other/unknown & $54(50.0)$ & $54(50.0)$ & & 3,4, and 5 & $6(46.2)$ & $7(53.9)$ & \\
\hline $\begin{array}{l}\text { Obesity, n (\%) } \\
\text { FIB-4 score, n (\%) }\end{array}$ & $87(44.4)$ & 109 (55.6) & $\begin{array}{r}0.010^{\mathrm{b}} \\
<0.001^{\mathrm{b}}\end{array}$ & HIV, n (\%) & $3(50.0)$ & $3(50.0)$ & $0.920^{\mathrm{b}}$ \\
\hline $0-3.25$ & $143(63.8)$ & $81(36.2)$ & & Baseline hospital/ED, n (\%) & $60(48.0)$ & $65(52.0)$ & $0.290^{\mathrm{b}}$ \\
\hline$>3.25$ & $20(28.6)$ & $50(71.4)$ & & Prescription count (unique generic drugs) & & & $0.040^{a}$ \\
\hline Unknown & $89(46.8)$ & $101(53.2)$ & & Mean (SD) & $14.9(19.2)$ & $17.1(20.0)$ & \\
\hline \multicolumn{4}{|l|}{ Laboratory tests } & Median & 8 & 10 & \\
\hline $\operatorname{ALT}(\mathrm{n})$ & 248 & 207 & $0.001^{\mathrm{a}}$ & Total outpatient visits & & & $0.620^{\mathrm{a}}$ \\
\hline Mean (SD) & $99.1(77.8)$ & $113.2(75.6)$ & & Mean (SD) & $12.4(15.1)$ & $13.0(16.7)$ & \\
\hline Median & 73 & 95 & & Median & 8 & 8 & \\
\hline AST (n) & 198 & 175 & $<0.001^{\mathrm{a}}$ & Treatment duration (weeks) & & & $<0.001^{\mathrm{a}}$ \\
\hline Mean (SD) & $72.2(58.6)$ & $87.9(59.6)$ & & Mean (SD) & $29.2(12.6)$ & $25.1(13.8)$ & \\
\hline Median & 50 & 72 & & Median & 25 & 24 & \\
\hline Platelet count (n) & 245 & 208 & $<0.001^{\mathrm{a}}$ & Weighted CCI, n (\%) & & & $<0.001^{b}$ \\
\hline Mean (SD) & $215.8(73.2)$ & $172.7(73.0)$ & & Weighted $\mathrm{CCI} \leq 1$ & $213(57.3)$ & $159(42.7)$ & \\
\hline Median & 211 & 169 & & Weighted $\mathrm{CCI}>1$ & $39(34.8)$ & $73(65.2)$ & \\
\hline \multicolumn{8}{|c|}{$\begin{array}{l}\text { aP values from Wilcoxon test. } \\
\text { bP values from chi-square test. } \\
\text { ALT = alanine aminotransferase; } A S T=\text { aspartate aminotransferase; } C C I=\text { Charlson Comorbidity Index; } C K D=\text { chronic kidney disease; } E D=\text { emergency department; } \\
\text { HCV=hepatitis } C \text { virus; } H I V=\text { human immunodeficiency virus; } I U / m L=\text { international units per milliliter; } S D=\text { standard deviation; } S V R=\text { sustained virologic response. }\end{array}$} \\
\hline
\end{tabular}

and found a low SVR rate, lends support to the growing consensus that genotype 3 is difficult to treat. The relapse rate of $23.5 \%$, found in this study, is also higher than the relapse rates reported by others, which generally range from $10 \%$ to $15 \% .^{11,13,15-18}$ Sofosbuvir was approved for use with ribavirin at the end of the study window, and patients treated with this new combination are only now completing therapy. Clinical studies suggest that the combination of sofosbuvir and ribavirin are equivalent or better than PegINF and ribavirin..$^{28,29}$ For treatment-naive genotype 3 patients, current national guidelines suggest sofosbuvir and ribavirin or the combination of sofosbuvir and ribavirin plus PegINF. ${ }^{30}$

\section{Limitations}

Several limitations need to be considered when interpreting our results. First, although we are reporting on $484 \mathrm{HCV}$ genotype 3 patients, it is a relatively small population resulting in ORs with large 95\% CI levels. As a result, although most point estimates for the baseline patient conditions were in the expected direction, the number of patients may have been too small for some factors to reach statistical significance. Second, treatment regimens were based on pharmacy refill records, and although refill records do not confirm drug-taking behavior, these records are commonly used in observational studies. The dispense data from our patients suggested that for a high percentage of their time on therapy, patients had drug in hand. Third, the diagnosis codes used to identify the patient population and determine baseline characteristics were not confirmed by chart review. Although we did not validate diagnosis codes through chart review, the data available through the EMR provided multiple sources for identifying patients and comorbid conditions. For example, we were able to use genotype data, HCV-RNA results, and diagnosis codes to identify our population of patients, and for patients with 


\section{TABLE 3 Multivariate Logistic Regression Results Factors Associated with Achieving SVR}

\begin{tabular}{l|c|c|c}
\hline \multirow{2}{*}{$\begin{array}{l}\text { Baseline Patient } \\
\text { Characteristics }\end{array}$} & \multicolumn{3}{|c}{ Logistic Regression Results } \\
\cline { 2 - 4 } & Odds Ratio & \multicolumn{2}{|c}{ 95\% CI } \\
\cline { 2 - 4 } Age $(\geq 45$ vs. $<45$ years) & Estimate & Lower & Upper \\
\hline Sex (male vs. female) & 0.57 & 0.37 & 0.88 \\
\hline Race & 0.64 & 0.42 & 0.98 \\
\hline White & 1.00 & \multicolumn{3}{|c}{ Reference } \\
\hline Hispanic and black & 1.05 & 0.65 & 1.71 \\
\hline All other races & 0.84 & 0.52 & 1.37 \\
\hline Medical conditions & \multicolumn{3}{|c}{} \\
\hline Pulmonary disease (COPD) & 0.39 & 0.19 & 0.80 \\
\hline Diabetes & 0.34 & 0.17 & 0.69 \\
\hline CKD (3, 4, or 5 vs. 1 and 2$)$ & 0.60 & 0.19 & 1.94 \\
\hline Obesity & 0.74 & 0.49 & 1.10 \\
\hline Cirrhosis & 0.31 & 0.15 & 0.61 \\
\hline Prior HCV treatment & 0.89 & 0.36 & 2.21 \\
\hline Baseline viral load $(\geq 400,000)$ & 0.83 & 0.56 & 1.22 \\
\hline Weighted CCI $\leq 1$ vs. >1) & 1.15 & 0.65 & 2.05 \\
\hline Hospitalization or ED visit & 0.94 & 0.60 & 1.49 \\
\hline
\end{tabular}

a Hosmer-Lemeshow goodness-of-fit test $P=0.79$.

$C C I=$ Charlson Comorbidity Index; $C I=$ confidence interval; $C K D=$ chronic kidney disease $; C O P D=$ chronic obstructive pulmonary disease; $E D=$ emergency department; $H C V=$ hepatitis $C$ virus; $S V R=$ sustained virologic response.

obesity, we were able to use diagnosis codes plus body mass index (measured height and weight from the EMR). Fourth, we had very few patients in our study with liver transplant, coinfection with HIV, African American (black) race, or with chronic kidney disease. Therefore, no associations can be drawn regarding these populations of patients.

Prior HCV treatment is generally associated with lower rates of SVR, and while a higher percentage of patients with prior treatment were in the treatment failure group for this study, these results and those of the multivariable analysis did not reach statistical significance. A post hoc subgroup analysis was therefore conducted in a population of treatment-naive patients; patients with prior HCV treatment were excluded from this analysis. The overall SVR rate, in this treatment-naive patient population, was not different from the whole cohort (52.5\% vs. $52.1 \%$ ), and minimal differences were seen in the multivariable analysis (data not shown).

\section{Conclusions}

Our results suggest that HCV genotype 3 patients treated in a real-world setting may not achieve the same rates of SVR as reported from clinical trials and from tertiary or referral care centers. The patients with lower SVR rates included those with severe liver disease or comorbid conditions such as diabetes and pulmonary disease. Male patients and those older than
45 years (primarily baby boomers born between 1946 and 1964) also had higher SVR failure rates. Treatment failures in this study seemed to be driven by higher rates of relapse and a higher percentage of patients lost to follow-up. Overall, these findings lend support to evidence suggesting genotype 3 may be more difficult to treat than originally thought and that treatment strategies may need to be adjusted for patients with genotype 3 . This is also important if, as some evidence suggests, patients with genotype 3 are at a higher risk for liver complications.

\section{Authors}

T. CRAIG CHEETHAM, PharmD, MS, is Research Scientist, and RULIN HECHTER, MD, PhD, is Research Scientist, Research E Evaluation Department, Southern California Permanente Medical Group, Pasadena, California. FANG NIU, MS, is Statistician, Drug Information Service, Kaiser Permanente Southern California, Downey, California; KEVIN CHIANG, PharmD, MBA, is Project Manager, Pharmacy Analytical Services, Kaiser Permanente Southern California, Downey, California; JOEL W. HAY, PhD, is Professor of Clinical Pharmacy and Pharmaceutical Economics and Policy, University of Southern California School of Pharmacy, Los Angeles; and LISA NYBERG, MD, MPH, is Director, Hepatology Research, Southern California Permanente Medical Group, San Diego, California. YONG YUAN, PhD, is Director, and ANU KALSEKAR, MS, is Group Director, Worldwide Health Economics and Outcomes Research, Bristol-Myers Squibb, Princeton, New Jersey.

AUTHOR CORRESPONDENCE: T. Craig Cheetham, PharmD, MS, 100 S. Los Robles Ave., 2nd Fl., Pasadena, CA 91101-2453.

Tel.: 626.564.3913; Fax: 626.564.3409; E-mail: Craig.T.Cheetham@kp.org.

\section{DISCLOSURES}

This research was funded by a grant from Bristol-Myers Squibb, Princeton, New Jersey. Yuan and Kalsekar are employees of Bristol-Myers Squibb. The other authors have no financial conflicts to report.

Study concept and design were contributed by Cheetham, Yuan, Kalsekar, Hechter, and Nyberg, with assistance from Hay and Niu. Niu and Chang collected the data, which were interpreted by Cheetham, Kalsekar, Hechter, Hay, and Nyberg, with assistance from Niu and Chiang. The manuscript was written primarily by Cheetham, with assistance from Niu, and revised by Yuan, Kalsekar, Hay, Nyber, and Hechter, with assistance from Chiang.

\section{REFERENCES}

1. Ditah I, Ditah F, Devaki P, et al. The changing epidemiology of hepatitis $C$ virus infection in the United States: National Health and Nutrition Examination Survey 2001 through 2010. J Hepatol. 2014;60(4):691-98.

2. Centers for Disease Control and Prevention. Hepatitis C FAQs for the public. Updated May 31, 2015. Available at: http://www.cdc.gov/hepatitis/c/ cfaq.htm. Accessed June 13, 2015.

3. Germer JJ, Mandrekar JN, Bendel JL, Mitchell PS, Yao JD. Hepatitis C virus genotypes in clinical specimens tested at a national reference testing laboratory in the United States. J Clin Microbiol. 2011;49(8):3040-43. 
4. Manos MM, Shvachko VA, Murphy RC, Arduino JM, Shire NJ. Distribution of hepatitis $C$ virus genotypes in a diverse U.S. integrated health care population. J Med Virol. 2012;84(11):1744-50.

5. Young AM, Crosby RA, Oser CB, Leukefeld CG, Stephens DB, Havens JR. Hepatitis $C$ viremia and genotype distribution among a sample of nonmedical prescription drug users exposed to HCV in rural Appalachia. J Med Virol. 2012;84(9):1376-87.

6. Bochud PY, Cai T, Overbeck K, et al. Genotype 3 is associated with accelerated fibrosis progression in chronic hepatitis C. J Hepatol. 2009;51(4):655-66.

7. Probst A, Dang T, Bochud M, Egger M, Negro F, Bochud PY. Role of hepatitis $C$ virus genotype 3 in liver fibrosis progression-a systematic review and meta-analysis. J Viral Hepat. 2011;18(11):745-59.

8. Nkontchou G, Ziol M, Aout M, et al. HCV genotype 3 is associated with a higher hepatocellular carcinoma incidence in patients with ongoing viral C cirrhosis. J Viral Hepat. 2011;18(10):e516-22.

9. Kanwal F, Kramer JR, Ilyas J, Duan Z, El-Serag HB. HCV genotype 3 is associated with an increased risk of cirrhosis and hepatocellular cancer in a national sample of U.S. veterans with HCV. Hepatology. 2014;60(1):98-105.

10. Mccombs J, Matsuda T, Tonnu-Mihara I, et al. The risk of long-term morbidity and mortality in patients with chronic hepatitis C: results from an analysis of data from a Department of Veterans Affairs Clinical Registry. JAMA Intern Med. 2014;174(2):204-12.

11. Shoeb D, Dearden J, Weatherall A, et al. Extended duration therapy with pegylated interferon and ribavirin for patients with genotype 3 hepatitis $C$ and advanced fibrosis: final results from the STEPS trial. J Hepatol. 2014;60(4):699-705.

12. Alvarez-Uria G, Day JN, Nasir AJ, Russell SK, Vilar FJ. Factors associated with treatment failure of patients with psychiatric diseases and injecting drug users in the treatment of genotype 2 or 3 hepatitis $C$ chronic infection. Liver Int. 2009;29(7):1051-55.

13. Zeuzem S, Hultcrantz R, Bourliere M, et al. Peginterferon alfa-2b plus ribavirin for treatment of chronic hepatitis $C$ in previously untreated patients infected with HCV genotypes 2 or 3. J Hepatol. 2004;40(6):993-99.

14. Poustchi H, Negro F, Hui J, et al. Insulin resistance and response to therapy in patients infected with chronic hepatitis $C$ virus genotypes 2 and 3. J Hepatol. 2008;48(1):28-34.

15. Elefsiniotis IS, Pantazis KD, Dimitroulopoulos D, Koutsounas S, Moulakakis A, Paraskevas E. Impact of shorter duration of treatment on virological response rate in genotype 2 or 3 chronic hepatitis $C$ virus infection. Indian J Gastroenterol. 2007;26(5):209-13.

16. Shah SR, Patel K, Marcellin P, et al. Steatosis is an independent predictor of relapse following rapid virologic response in patients with HCV genotype 3 Clin Gastroenterol Hepatol. 2011;9(8):688-93.
17. Shoeb D, Rowe IA, Freshwater D, et al. Response to antiviral therapy in patients with genotype 3 chronic hepatitis $C$ : fibrosis but not race encourages relapse. Eur J Gastroenterol Hepatol. 2011;23(9):747-53.

18. Shiffman ML, Mihas AA, Millwala F, et al. Treatment of chronic hepatitis $C$ virus in African Americans with genotypes 2 and 3. Am J Gastroenterol. 2007;102(4):761-66

19. Koebnick C, Langer-Gould AM, Gould MK, et al. Sociodemographic characteristics of members of a large, integrated health care system: comparison with U.S. Census Bureau data. Perm J. 2012;16(3):37-41.

20. Vallet-Pichard A, Mallet V, Nalpas B, et al. FIB-4: an inexpensive and accurate marker of fibrosis in HCV infection. Comparison with liver biopsy and fibrotest. Hepatology. 2007;46(1):32-36.

21. Romano PS, Roos LL, Jollis JG. Adapting a clinical comorbidity index for use with ICD-9-CM administrative data: differing perspectives. J Clin Epidemiol. 1993;46(10):1075-79.

22. Romano PS, Roos LL, Jollis JG. Further evidence concerning the use of a clinical comorbidity index with ICD-9-CM administrative data. J Clin Epidemiol. 1993;46(10):1085-90.

23. Quan H, Sundararajan V, Halfon P, et al. Coding algorithms for defining comorbidities in ICD-9-CM and ICD-10 administrative data. Med Care. 2005;43(11):1130-39.

24. von Wagner M, Huber M, Berg T, Hinrichsen H, et al. Peginterferonalpha-2a (40KD) and ribavirin for 16 or 24 weeks in patients with genotype 2 or 3 chronic hepatitis C. Gastroenterology. 2005;129(2):522-27.

25. Alsiö A, Rembeck K, Askarieh G, et al. Impact of obesity on the bioavailability of peginterferon-alpha2a and ribavirin and treatment outcome for chronic hepatitis C genotype 2 or 3. PLoS One. 2012;7(5):e37521.

26. Ampuero J, Romero-Gómez M, Reddy KR. Review article: HCV genotype 3: the new treatment challenge. Aliment Pharmacol Ther. 2014;39(7):686-98.

27. Goossens N, Negro F. Is genotype 3 of the hepatitis $C$ virus the new villain? Hepatology. 2014;59(6):2403-12.

28. Jacobson IM, Gordon SC, Kowdley KV, et al. Sofosbuvir for hepatitis C genotype 2 or 3 in patients without treatment options. N Engl J Med. 2013;368(20):1867-77.

29. Zeuzem S, Dusheiko GM, Salupere R, et al. Sofosbuvir and ribavirin in HCV genotypes 2 and 3. N Engl J Med. 2014;370(21):1993-2001.

30. American Association for the Study of Liver Diseases, Infectious Diseases Society of America. Recommendations for testing, managing, and treating hepatitis C. January 26, 2015. Available at: http://www.hcvguidelines.org/full-report-view. Accessed June 14, 2015. 